\title{
The Stoppa combined with iliac fossa approach for the treatment of both-column acetabular fractures
}

\author{
Yun Yang ${ }^{\dagger}$, Chang Zou ${ }^{\dagger}$ and Yue Fang ${ }^{*}$
}

\begin{abstract}
Background: At present, the choice of surgical approach for both-column fractures is still controversial. The purpose of this study was to explore the efficacy of the Stoppa combined with iliac fossa (S+IF) approach in the treatment of both-column fractures.

Methods: In this retrospective case series, 76 patients were included in the study from 2014 to 2018. They were divided into two groups according to the surgical approaches. The differences of intraoperative blood loss, operative time, quality of reduction, clinical outcome, and perioperative complications were compared between the two groups.

Results: All patients had undergone the IL approach or the S+IF approach. The average operative time was 156.2 min (110 210 min) in group I and $126.5 \mathrm{~min}(80 \sim 180 \mathrm{~min})$ in group II $(P<0.001)$. The average blood loss in group I was $784.1 \mathrm{ml}$, while the average blood loss in group II was $625.3 \mathrm{ml}(P=0.007)$. According to Matta's criteria, 28 cases obtained anatomic reduction and 12 cases got imperfect reduction in group l; 21 cases obtained anatomic reduction and 7 cases got imperfect reduction in group $\|(P>0.05)$. The clinical outcome (excellent to good) was $66 \%$ in group I versus $69 \%$ in group II $(P>0.05)$. The complication rates were $18.2 \%$ in group I and $12.5 \%$ in group II $(P>0.05)$.

Conclusions: As a minimally invasive surgical approach, the S+IF approach is a valuable alternative to the IL approach for the treatment of both-column acetabular fractures if these two anterior approaches can achieve fracture exposure, reduction, and fixation.
\end{abstract}

Keywords: Acetabular fracture, Both columns, Stoppa approach, Iliac fossa approach, llioinguinal approach, Internal fixation

\section{Background}

Both-column fractures account for about $20 \%$ of the total number of acetabular fractures, which are characterized by no articular fragment in connection with the axial skeleton and fracture lines involving multiple planes [1-3]. In the treatment of acetabular fractures,

\footnotetext{
*Correspondence: fangyue1968@163.com

${ }^{\dagger}$ Yun Yang and Chang Zou contributed equally to this work. Department of Orthopaedics, West China Hospital, Sichuan University, Chengdu, Sichuan, People's Republic of China
}

anatomical reduction and rigid internal fixation are very critical to obtain a good outcome [3-6]. In order to achieve accurate reduction and minimize complications, it is necessary to choose the appropriate surgical approach.

The choice of surgical approach for both-column fractures is still controversial. The IL approach is the standard anatomic approach for most both-column fractures [7] and enables direct visualization of the anterior column up to the symphysis pubis. The exposure of the

(c) The Author(s). 2020 Open Access This article is licensed under a Creative Commons Attribution 4.0 International License, which permits use, sharing, adaptation, distribution and reproduction in any medium or format, as long as you give appropriate credit to the original author(s) and the source, provide a link to the Creative Commons licence, and indicate if changes were made. The images or other third party material in this article are included in the article's Creative Commons licence, unless indicated otherwise in a credit line to the material. If material is not included in the article's Creative Commons licence and your intended use is not permitted by statutory regulation or exceeds the permitted use, you will need to obtain permission directly from the copyright holder. To view a copy of this licence, visit http://creativecommons.org/licenses/by/4.0/. The Creative Commons Public Domain Dedication waiver (http://creativecommons.org/publicdomain/zero/1.0/) applies to the data made available in this article, unless otherwise stated in a credit line to the data. 
quadrilateral plate via the IL approach can only be achieved by palpation of the endopelvic finger. Some scholars actively explore a single approach to treat this complex injury [8-11]. Others are skeptical that neither the IL nor the Kocher-Langenbeck (KL) approach alone can expose all of the fragments [12-14]. However, extensile approaches are associated with higher rates of complications [13-15]. Therefore, limited exposure is necessary to optimize treatment and reduce complications. The Stoppa approach, as a midline approach, can provide direct exposure of the area from the sacroiliac joint to the pubic symphysis (including the quadrilateral plate) $[6,16]$. However, it does not expose the iliac wing and is sometimes combined with the lateral window of the IL approach to treat complex acetabular fractures $[17,18]$.

To overcome the respective limitations of the IL and Stoppa approaches, we have treated complex acetabular fractures through the S+IF approach in recent years. Moreover, there is little literature on the treatment of both-column fractures by S+IF approach. Therefore, the aim of this study was to investigate the clinical efficacy of the S+IF approach in the treatment of both-column fractures by comparing with the IL approach.

\section{Materials and methods}

\section{Materials}

From January 2014 to January 2018, we retrospectively studied 98 patients with acetabular fractures. Inclusion criteria were (1) acute both-column fracture and (2) fractures treated with the S+IF or IL surgical approach. The exclusion criteria were (1) fractures treated via the combined anterior and posterior approaches, (2) preoperative range of motion (ROM) deficiency of the hip, (3) open fractures, (4) less than 1 year of follow-up, (5) conservative treatment, and patients with a history of bladder surgery, hysterectomy, cesarean section, or prostatectomy. Overall, 76 patients met the criteria for inclusion. Data were collected through an anonymous way because the patients' identifiers such as name and unique identity were erased. This study was approved by the Ethics Committee and Institutional Review Board of West China Hospital.

All patients were studied with X-rays (anteroposterior and Judet oblique views) and CT scan with 3D reconstruction for classification of acetabular fractures. Preoperative skeletal traction was conducted on the affected side to guard against further injury to the femoral head. All patients were treated by the same medical team.

These patients were divided into two groups according to the surgical approaches. The first group included 44 patients treated by the IL approach (group I), while the second group of 32 patients were treated by the S+IF approach (group II).

\section{Surgical technique \\ IL approach}

The incision of the IL approach began at the middle of iliac crest and was anteriorly and distally extending to the anterior superior iliac spine (ASIS) and the pubic tubercle (Fig. 1). The IL approach was divided into three windows by lacuna vasorum and lacuna musculorum. The lateral window could be exposed by subperiosteal dissection of the abdominal muscle and iliac muscle. The aponeurosis of the external oblique was carved to identify and dissociate the external ring of inguinal canal and expose the medial window. The aponeurosis of the internal oblique was incised, followed by a wide drainage film to free and protect the femoral vessels, femoral nerve, lymphatic vessels, and conjunctive tendon. Finally, the iliopubic fascia was separated and cut to expose the middle window. After satisfactory reduction was accomplished, a prebent plate was placed for fixation.

\section{S+IF approach}

The patient who received the S+IF approach (Fig. 2) was placed in the supine position. The incision of the Stoppa approach was performed in the region $1 \sim 2 \mathrm{~cm}$ above the pubic symphysis. The bladder was protected, and the rectus abdominis was retracted to expose the pubic symphysis and the superior ramus of the pubis. The rectus abdominis and neurovascular bundle were then retracted laterally to protect them. If corona mortis was encountered, ligation should be performed. The iliopubic fascia and obturator fascia were incisively dissected from the front to the back to expose the true pelvic rim, the quadrilateral plate, and the posterior column of the acetabulum. The ischial support band and the back of the pelvic rim could be better exposed by stripping the psoas muscle. The IF approach (the lateral window of the IL approach) began at the middle of the iliac crest to the ASIS. The exposure of the iliac wing could be achieved by retracting the iliac muscle and iliac vessels, and the exposure could be improved by flexion, rotation, adduction, and abduction of the affected hip. Reduction techniques included the use of a ball-spiked pusher to provide an outward force, the insertion of a Hohmann lever at the greater sciatic notch to pry out the posterior column and femoral traction, or the use of traction bed for longitudinal traction.

\section{Follow-up and evaluation criteria}

The patients' charts were surveyed for intraoperative blood loss, operative time, quality of reduction, clinical outcome, and perioperative complications. The quality of the reduction was evaluated based on the immediately postoperative radiographs. It was graded as anatomic, imperfect, and poor according to the scoring system published by Matta [4]. 


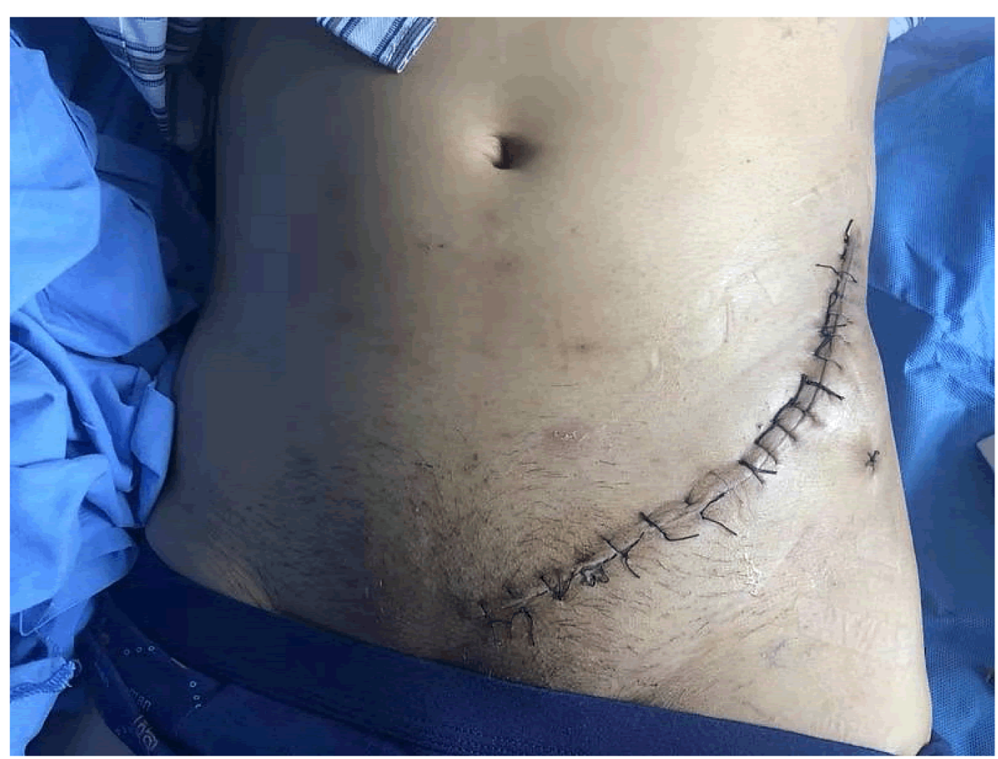

Fig. 1 Surgical incision of the IL approach

Follow-up was performed at 1, 2, and 3 months and 1 year after surgery and yearly thereafter. Clinical outcomes were measured using the Matta modification of the Merle D'Aubigne score [7, 19]. Complications such as infection, neurovascular injuries, and hematoma were also recorded.

\section{Statistical analysis}

Statistical analysis was done using the SPSS 20.0 software (SPSS Chicago, IL, USA). The results were presented as the mean \pm standard deviation. The complication rates of two groups were determined by chisquare test. Other differences between the two groups were determined by $t$ tests. A value of $P \leq 0.05$ was considered to be statistically significant.

\section{Results}

\section{The demographics of subjects}

All fractures were fixed via the IL approach (44 cases) or the S+IF approach (32 cases). There were $47(62 \%)$

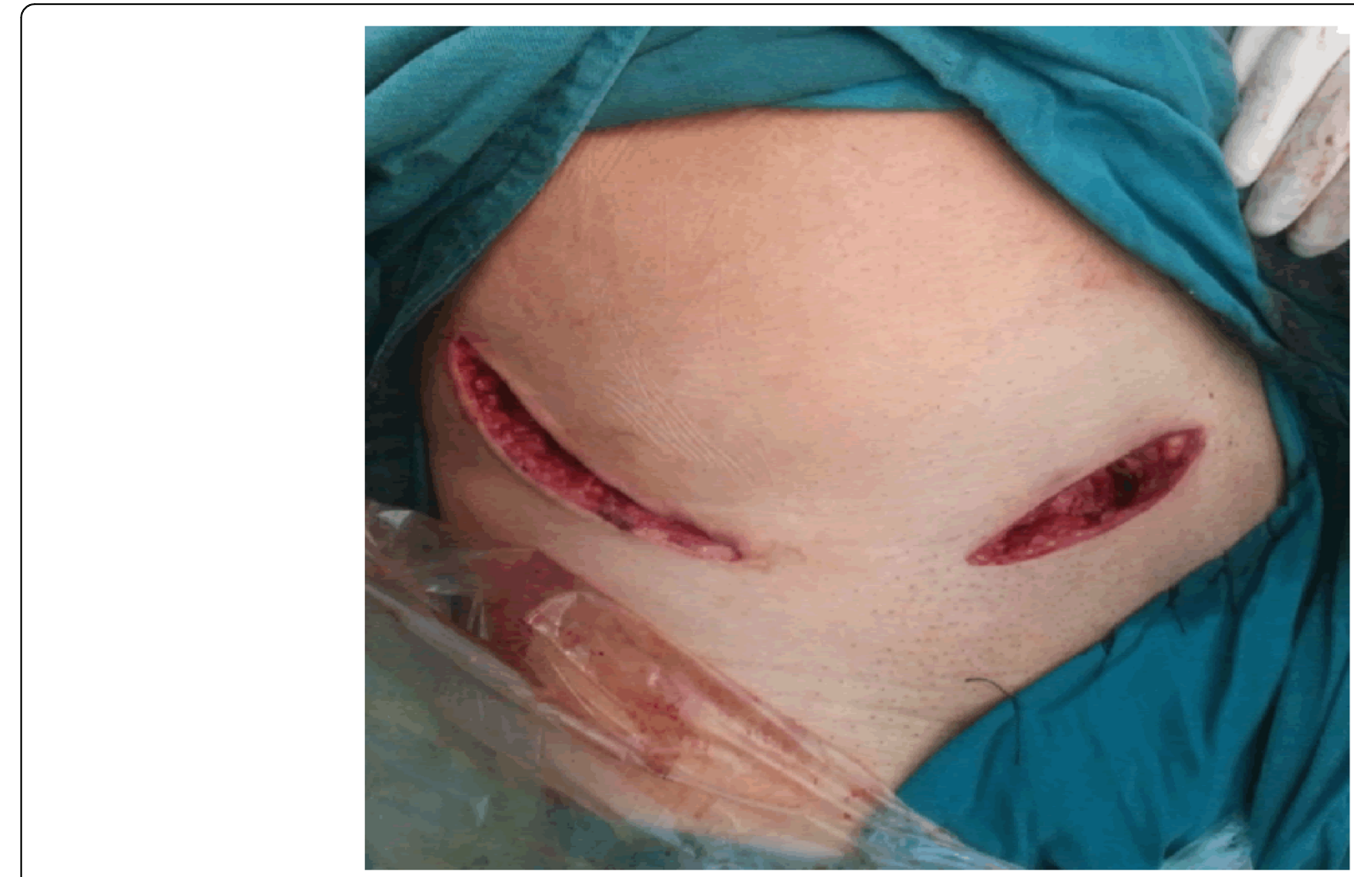

Fig. 2 Surgical incision of the S+IF approach 
males and 29 (38\%) females included in this study with an average age of 41 years (range 18 75 years). The most common mechanism of injury was a high-energy mechanism-fall from height. The mean follow-up was 26 months (range 12 36 months). The difference of general characteristics between the two groups was not statistically significant (Table 1 ).

\section{Comparison of surgical-related parameters}

The average blood loss in group I was $784.1 \mathrm{ml}$, while the average blood loss in group II was $625.3 \mathrm{ml}(P=$ $0.007)$. The mean operative time was longer in group I as compared to group II $(P<0.001)$. There was no secondary congruence for the reduction in this study. The quality of reduction was similar between the two groups $(P=0.806)$. The clinical outcome (excellent to good) was $66 \%$ in group I versus $69 \%$ in group II, and the difference was not statistically significant (Table 2).

\section{Comparison of complications}

The complication rates were $18.2 \%$ in group I (8 cases) and $12.5 \%$ in group II $(4$ cases $)(P=0.502)$ (Table 3). There were three cases of lateral femoral cutaneous nerve (LFCN) palsy with 3 6 months resolution in group I. Femoral nerve palsy developed in one patient, and this case showed part recovery after 1 year. Femoral vascular injury occurred in one patient. Hematoma and surgical wound infection appeared in one and two patients, respectively, with the symptoms disappearing after conservative treatment (puncture and antibiotics, respectively). In group II, LFCN palsy existed in two cases postoperatively, and the symptoms disappeared after 4 months of

Table 1 The demographics of subjects

\begin{tabular}{|c|c|c|c|}
\hline \multirow[t]{2}{*}{ Variable } & \multicolumn{2}{|l|}{ Group } & \multirow{2}{*}{$\begin{array}{l}P \\
\text { value }\end{array}$} \\
\hline & 1 & II & \\
\hline Age $(M \pm S D)$, year & $41.89 \pm 14.19$ & $39.94 \pm 15.21$ & 0.405 \\
\hline \multicolumn{4}{|l|}{ Gender, $n(\%)$} \\
\hline Men & $27(61)$ & $20(62)$ & \multirow[t]{2}{*}{0.920} \\
\hline Women & $17(39)$ & $12(38)$ & \\
\hline \multicolumn{4}{|l|}{ Side of injury, $n$ (\%) } \\
\hline Right & $26(59)$ & $15(47)$ & \multirow[t]{3}{*}{0.291} \\
\hline Left & $18(41)$ & $17(53)$ & \\
\hline Bilateral & $0(0)$ & $0(0)$ & \\
\hline \multicolumn{4}{|l|}{ Mechanism of injury, $n$ (\%) } \\
\hline Motor vehicle collision & 15(34) & $12(38)$ & \multirow[t]{3}{*}{0.763} \\
\hline Fall from height & $26(59)$ & $19(59)$ & \\
\hline Others & $3(7)$ & $1(3)$ & \\
\hline Total & 44 & 32 & - \\
\hline
\end{tabular}

Table 2 Analysis of the results between the two groups

\begin{tabular}{|c|c|c|c|}
\hline \multirow[t]{2}{*}{ Variable } & \multicolumn{2}{|l|}{ Group } & \multirow{2}{*}{$\begin{array}{l}P \\
\text { value }\end{array}$} \\
\hline & 1 & II & \\
\hline Blood loss (ml) & $784.09 \pm 277.70$ & $625.31 \pm 193.39$ & 0.007 \\
\hline Operative time (min) & $156.18 \pm 27.54$ & $126.53 \pm 29.56$ & $<0.001$ \\
\hline Reduction (mm) & & & 0.806 \\
\hline Anatomic (0-1) & $28(64 \%)$ & $21(66 \%)$ & \\
\hline Imperfect (2-3) & $12(27 \%)$ & $7(22 \%)$ & \\
\hline Poor (> 3) & $4(9 \%)$ & $4(12 \%)$ & \\
\hline Clinical outcome, score & & & 0.981 \\
\hline Excellent (15-18) & $21(48 \%)$ & $15(47 \%)$ & \\
\hline Good (11-14) & $8(18 \%)$ & $7(22 \%)$ & \\
\hline Fair (7-10) & $9(20 \%)$ & $6(19 \%)$ & \\
\hline Poor $(<7)$ & $6(14 \%)$ & $4(12 \%)$ & \\
\hline
\end{tabular}

nutritional neurotherapy. The obturator nerve was damaged in one case intraoperatively but had recovered 6 months after surgery. One patient had an iatrogenic laceration of the corona mortis during surgery. Nonunion heterotopic ossification was not observed in this study.

\section{Discussion}

Surgical approach is the key factor affecting the treatment effect of acetabular fractures [20]. The IL approach enables a wide view of the entire iliac surface, the iliac crest, and the sacroiliac joint anteriorly [21]. Its indications include fractures of the anterior wall, the anterior column, anterior column plus posterior hemitransverse, some $\mathrm{T}$ types, and most of the associated both-column fractures [7]. However, it just gives palpatory exposure of the quadrilateral plate and enables indirect exposure of the posterior column within the middle window. In addition, the learning curve is

Table 3 Comparison of perioperative complications between the two groups

\begin{tabular}{llll}
\hline Complications & Group & & $\begin{array}{c}\boldsymbol{P} \\
\text { value }\end{array}$ \\
\cline { 2 - 3 } & $\mathbf{I}$ & II & 0.502 \\
\hline LFCN palsy & 3 & 2 & \\
ON palsy & 0 & 1 & \\
FN palsy & 1 & 0 & \\
Vascular injury & 1 & 1 & \\
Hematoma & 1 & 0 & \\
Infection & 2 & 0 & \\
DVT & 0 & 0 & \\
Total & 8 & 4 & \\
\hline LFCN lateral femoral cutaneous nerve, ON obturator nerve, FN femoral nerve, \\
DVT deep vein thrombosis
\end{tabular}


quite steep due to critical anatomical structures. The Stoppa approach has been modified for the treatment of acetabular fractures. It can well expose the pelvic ring and the quadrilateral plate, which facilitates the fracture reduction at the quadrilateral plate. But the single Stoppa approach does not adequately expose and fix the iliac wing fracture, which could be exposed through the IF approach.

Considering the defects of the above surgical approaches, we combined the S+IF approach to treat acetabular fractures. There were few reports on the treatment of both-column fractures by the S+IF approach. Therefore, we compared the efficacy of the IL approach and the S+IF approach in the treatment of both-column fractures.

Compared with the IL+KL approach, the S+IF approach was less invasive and has less bleeding and less surgical time [22]. Ma et al. [23] found that the Stoppa approach reduced intraoperative blood loss and there were no significant differences in other measured variables by comparing the patients' demographics and the perioperative parameters between the Stoppa approach and the IL approach. Shazar et al. [24] found that the Stoppa approach was superior to the IL approach in terms of reduction accuracy. Rocca et al. [25] found the Anterior Combined Endopelvic (the Stoppa approach with the lateral approach to the iliac crest) approach and the IL approach were similar in reduction quality, while the ACE approach was more effective than the IL approach in clinical outcome and blood loss.

In the current study, fracture reduction was acceptable in $91 \%$ of cases (64\% anatomical, $27 \%$ imperfect) in group I (Fig. 3) and in $88 \%$ of cases (66\% anatomical, $22 \%$ imperfect) in group II (Fig. 4). The clinical outcome was similar between the two groups. Blood loss and operative time were significantly more in group I than in group II. These results were basically consistent with the above studies [22-25].

The overall rate of complications in our study was comparable to that found in the literature. Most scholars reported similar complications in their early cases [7, 26, 27]. Both the IL and Stoppa approaches were at risk of injury to blood vessels and nerves. LFCN was prone to iatrogenic injury due to its highly variable course and branches [28]. LFCN injury occurred in three patients in group I and two patients in group II. Our experience is that the separation of soft tissue along the iliac periosteum may be conducive to protect LFCN. In addition, vascular injury (femoral vascular versus corona mortis) and other nerve injury (femoral versus obturator) occurred in both groups. When corona mortis is encountered, ligation is recommended to avoid affecting the visibility of the fracture fissure. In this study, wound infection occurred in two patients $(2.6 \%)$ in group I, with wound healing after intensive dressing change and antibiotic use. But it is not clear whether there is a

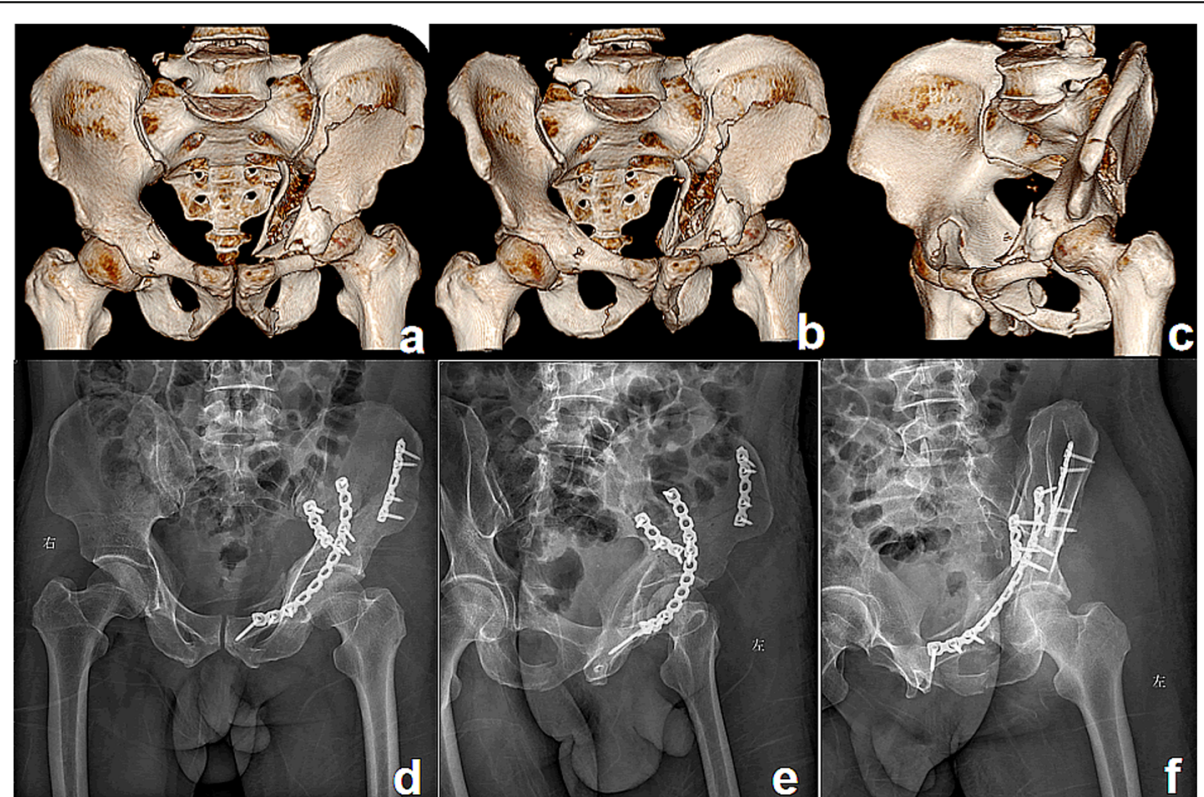

Fig. 3 A patient treated with the IL approach. Preoperative anteroposterior (a), iliac oblique (b), and obturator oblique (c) 3D computed tomography reconstructions of a both-column fracture showing the severity of fracture displacement. Postoperative radiographs (d-f) showing good reduction and fixation 


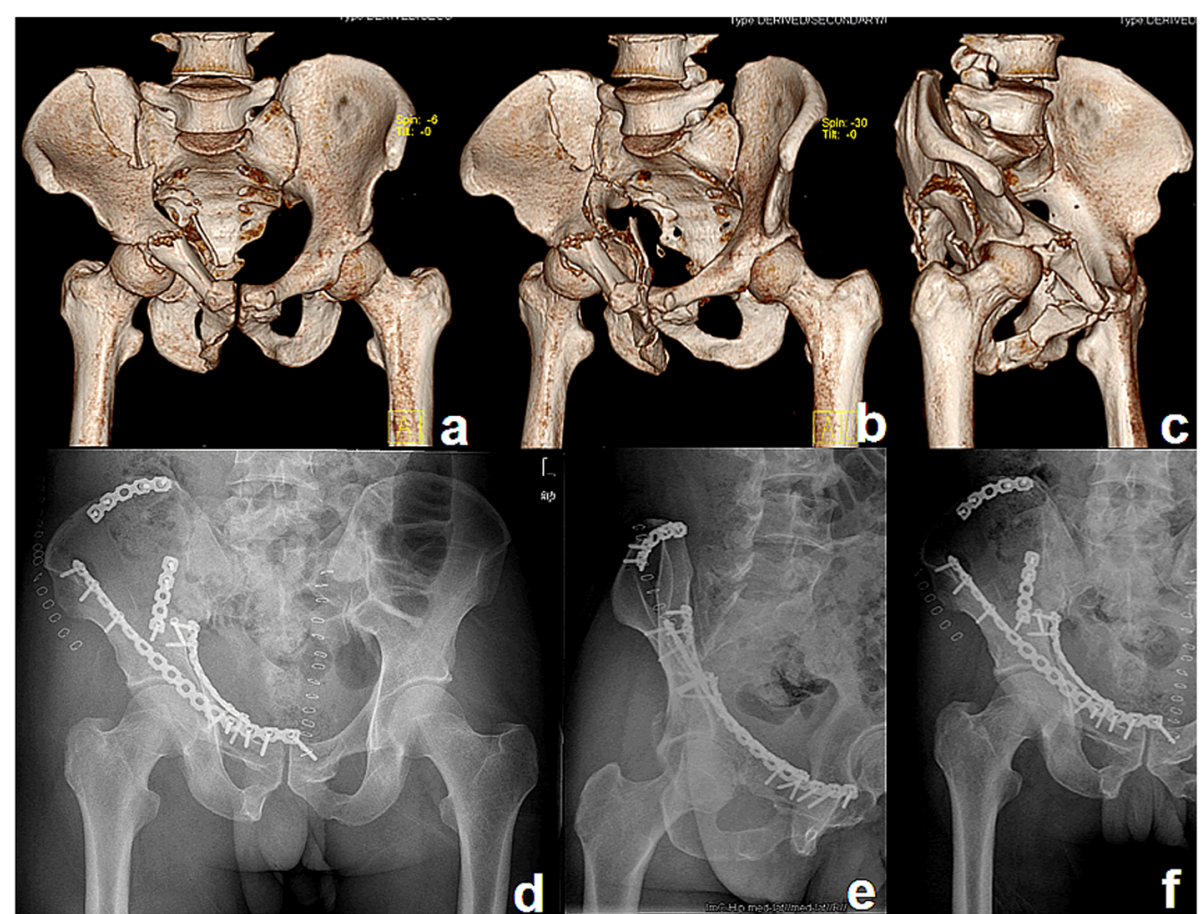

Fig. 4 A patient treated with the S+IF approach. Preoperative 3D computed tomography reconstructions (a-c) of a both-column fracture showing the severity of fracture displacement. Postoperative radiographs $(\mathbf{d}-\mathbf{f})$ showing good reduction and fixation

direct link between wound infection and surgical approach.

This study had also several limitations. As a retrospective study, patients were not randomly assigned. In addition, there were some shortcomings in this study, such as small sample size and short follow-up time, which need to be further improved to confirm the advantages of the S+IF approach in future research.

\section{Conclusions}

In conclusion, the $\mathrm{S}+\mathrm{IF}$ approach can fully expose the anterior column and the quadrilateral plate, which is conducive to the reduction and fixation of both-column fractures. Compared with the IL approach, the S+IF approach had the advantages of less blood loss and shorter operative time. In terms of reduction accuracy, clinical outcome, and fewer complications, there was no significant difference between the two approaches. In the management of both-column fractures, the S+IF approach is recommended if the S+IF approach and IL approach can achieve fracture exposure, reduction, and fixation.

\section{Abbreviations}

S+IF: Stoppa combined with iliac fossa; IL: Ilioinguinal; KL: KocherLangenbeck; ROM: Range of motion; CT: Computed tomography; 3D: Threedimensional; ASIS: Anterior superior iliac spine; LFCN: Lateral femoral cutaneous nerve; ACE: Anterior Combined Endopelvic

\section{Acknowledgements}

The authors thank Wen-zhu Li in providing language help.
Authors' contributions

YY and CZ carried out the study design and writing of the manuscript. CZ confirmed the completeness and validity of the data. YF was a major contributor in conception and design and revising it critically. YY made contributions in data collecting and drafting. All authors read and approved the final manuscript.

\section{Funding}

Not applicable.

\section{Availability of data and materials}

This article only includes summarized data from this study. Datasets are available from the corresponding author on reasonable request.

\section{Ethics approval and consent to participate}

This study was approved by the Ethics Committee and Institutional Review Board of West China Hospital.

\section{Consent for publication}

Not applicable.

\section{Competing interests}

The authors declare that they have no competing interests.

Received: 19 October 2020 Accepted: 29 November 2020 Published online: 07 December 2020

\section{References}

1. Rogers LF, Novy SB, Harris NF. Occult central fractures of the acetabulum. Am J Roentgenol Radium Ther Nucl Med. 1975;124:96-101.

2. Chen KN, Wang G, Cao LG, Zhang MC. Differences of percutaneous retrograde screw fixation of anterior column acetabular fractures between male and female: a study of 164 virtual three-dimensional models. Injury. 2009:40:1067-72.

3. Giannoudis PV, Grotz MR, Papakostidis C, Dinopoulos H. Operative treatment of displaced fractures of the acetabulum. A meta-analysis. J Bone Joint Surg Br. 2005;87:2-9. 
4. Matta JM. Fractures of the acetabulum: accuracy of reduction and clinical results in patients managed operatively within three weeks after the injury. J Bone Joint Surg Am. 1996;78:1632-45.

5. Mears DC, Velyvis JH, Chang CP. Displaced acetabular fractures managed operatively: indicators of outcome. Clin Orthop Relat Res. 2003;407:173-86.

6. Elmadag M, Guzel Y, Aksoy Y, Arazi M. Surgical treatment of displaced acetabular fractures using a modified Stoppa approach. Orthopedics. 2016;39:e340-5.

7. Matta JM. Operative treatment of acetabular fractures through the ilioinguinal approach. A 10-year perspective. Clin Orthop Relat Res. 1994; 305:10-9.

8. Ur Razaq MN, Khan MA, Ali A. Outcome of two column acetabular fractures treated operatively through single posterior approach. J Ayub Med Coll Abbottabad. 2016;28:718-20.

9. Wang $H$, Utku K, Zhuang $Y$, Zhang K, Fu YH, Wei X, et al. Post wall fixation by lag screw only in associated both column fractures with posterior wall involvement. Injury. 2017:48:1510-7.

10. Wang C, Liu H, Lin X, Chen J, Li T, Mai Q, et al. A single lateral rectus abdominis approach for the surgical treatment of complicated acetabular fractures: a clinical evaluation study of 59 patients. Med Sci Monit. 2018;24:7285-94.

11. Chen K, Ji Y, Huang Z, Navinduth R, Yang F, Sun T, et al. Single modified ilioinguinal approach for the treatment of acetabular fractures involving both columns. J Orthop Trauma. 2018:32:e428-34.

12. Pierannunzii L, Fischer F, Tagliabue L, Calori GM, d'mporzano M. Acetabular bothcolumn fractures: essentials of operative management. Injury. 2010:41:1145-9.

13. Harris AM, Althausen P, Kellam JF, Bosse MJ. Simultaneous anterior and posterior approaches for complex acetabular fractures. J Orthop Trauma. 2008;22:494-7

14. Guerado E, Cano JR, Cruz E. Simultaneous ilioinguinal and KocherLangenbeck approaches for the treatment of complex acetabular fractures Hip Int. 2010;20:S2-10.

15. Kothe M, Lein T, Weber AT, Bonnaire F. Morel-Lavalle'e lesion. A grave soft tissue injury. Unfallchirurg. 2006;109:82-6.

16. Kim HY, Yang DS, Park CK, Choy WS. Modified Stoppa approach for surgical treatment of acetabular fracture. Clin Orthop Surg. 2015;7:29-38.

17. Jakob M, Droeser R, Zobrist R, Messmer P, Regazzoni P. A less invasive anterior intrapelvic approach for the treatment of acetabular fractures and pelvic ring injuries. J Trauma. 2006;60:1364-70.

18. Wolf $H$, Wieland T, Pajenda G, Vecsei V, Mousavi M. Minimally invasive ilioinguinal approach to the acetabulum. Injury. 2007;38:1170-6.

19. Matta JM, Mehne DK, Roffi R. Fractures of the acetabulum. Early results of a prospective study. Clin Orthop Relat Res. 1986;205:241-50.

20. Zha GC, Sun JY, Dong SJ. Predictors of clinical outcomes after surgical treatment of displaced acetabular fractures in the elderly. J Orthop Res. 2013:31(4):588-95.

21. Fensky F, Lehmann W, Ruecker A, Rueger JM. llioinguinal approach: indication and technique. J Orthop Trauma. 2018:32:S12-3.

22. Zhang $R$, Yin $Y$, Li S, Hou Z, Wang J, Chen W, et al. Minimally invasive treatment of both-column acetabular fractures through the Stoppa combined with iliac fossa approach. Sci Rep. 2017;7(1):8044.

23. Ma K, Luan F, Wang X, Ao Y, Liang Y, Fang Y, et al. Randomized, controlled trial of the modified Stoppa versus the ilioinguinal approach for acetabular fractures. Orthopedics. 2013;36(10):e1307-15.

24. Shazar N, Eshed I, Ackshota N, Hershkovich O, Khazanov A, Herman A. Comparison of acetabular fracture reduction quality by the ilioinguinal or the anterior intrapelvic (modified Rives-Stoppa) surgical approaches. J Orthop Trauma. 2014;28(6):313-9.

25. Rocca G, Spina M, Mazzi M. Anterior Combined Endopelvic (ACE) approach for the treatment of acetabular and pelvic ring fractures: a new proposal. Injury. 2014;45:S9-15.

26. Letournel $E$. The treatment of acetabular fractures through the ilioinguinal approach. Clin Orthop Relat Res. 1993:292:62-76.

27. Sagi HC, Afsari A, Dziadosz D. The anterior intra-pelvic (modified RivesStoppa) approach for fixation of acetabular fractures. J Orthop Trauma. 2010;24(5):263-70

28. den Brave PS, Vas Nunes SE, Bronkhorst MW. Anatomical variations of the lateral femoral cutaneous nerve and iatrogenic injury after autologous bone grafting from the iliac crest. J Orthop Trauma. 2015;29(12):549-53.

\section{Publisher's Note}

Springer Nature remains neutral with regard to jurisdictional claims in published maps and institutional affiliations.

\section{Ready to submit your research? Choose BMC and benefit from:}

- fast, convenient online submission

- thorough peer review by experienced researchers in your field

- rapid publication on acceptance

- support for research data, including large and complex data types

- gold Open Access which fosters wider collaboration and increased citations

- maximum visibility for your research: over $100 \mathrm{M}$ website views per year

At BMC, research is always in progress.

Learn more biomedcentral.com/submissions 